\title{
CONTAR PARA QUÊ E CONTAR PARA QUEM: DIÁLOGO E ARQUITETÔNICA NA LEITURA, LITERATURA E FORMAÇÃO DE PROFESSORES
}

\author{
TELLING WHAT FOR AND TO WHOM: DIALOGUE AND \\ ARCHITECTONICS IN READING, LITERATURE AND TEACHER \\ EDUCATION
}

Marco Antonio VILLARTA-NEDER ${ }^{1}$

\begin{abstract}
Resumo
O objetivo deste artigo é discutir aspectos da natureza do processo de contar histórias e estabelecer relações com a leitura, literatura e a formação de professores da Educação Básica. Partimos do referencial teórico-epistemológico do Círculo de Bakhtin, para o qual as noções centrais são a de diálogo e alteridade. Nesse âmbito, procuramos situar a contação de histórias dentro do contexto enunciativo: há que se contar em função de uma necessidade interacional com o outro e para esse outro. $\mathrm{O}$ conceito bakhtiniano de arquitetônica permite abordar as nuances dessa relação intersubjetiva: no circuito de produção, circulação e recepção de sentidos, há, também um movimento de posições representadas subjetivamente: a do próprio sujeito (eu-para-mim), a do interlocutor (outro-para-mim) e a projeção de como o outro estaria representando o sujeito falante/contante. A literatura pode ser vista constituindo-se como um ato em que os sujeitos se posicionam como testemunhas desse jogo de gestos e projetos de sentido. O papel do professor é se pensar no interior dessa arquitetônica é duplo: sujeito participante desse circuito de produção/circulação/recepção de sentidos e mediador, como quem convida os alunos a dialogarem com ele, com eles mesmos e com o mundo.
\end{abstract}

Palavras-chave: Contação de histórias. Círculo de Bakhtin. Arquitetônica. Discurso. Formação de Professores.

\begin{abstract}
The aim of this text is to discuss aspects of storytelling's nature and to establish relations with reading, literature and teachers education at Basic Education level in Brazil. We start this discussion from Bakhtin's Circle theorethical bias, to whom the main notions are dialogue and alterity. Thus we intend to put out storytelling within enunciative contexto. Bakhtinian concept of architectonics allows to face several aspects of this intersubjective relation: in the production, circulation and reception circuit of meaning there is, also, a movement of positions representing subjectivally: the person itself (I-for-myself), the other (the-other-for-
\end{abstract}

${ }^{1}$ Universidade Federal de Lavras (GEPLE/LEDISC/GEDISC). Lavras, Minas Gerais, Brasil. E-mail: villarta.marco@del.ufla.br

Revista Devir Educação, Lavras, vol.2, n.1, p.55-67, jan./jun., 2018. 


\section{Q DEVIR EDUCAÇÃO}

ISSN: 2526-849X

me) and the projection of how the other would be building a representation of the person who speaks/who tells (I-for-the-other). Literature can be seen as a act in which the people take their places like witnesses of this play of gestures and meaning plannings. Teacher's role is, therefore, to see itself within this architectonics as a double perspective: at one time, as a partaker of this production, circulation and reception circuit of meaning and, at another hand, as a mediator, inviting their students to take part with the teacher, with themselves and with the world.

Keywords: Storytelling. Bakhtin`s Circle. Architectonics. Discourse. Teachers Education.

\section{Era uma vez}

O objetivo dessa discussão é traçar um percurso axiológico ${ }^{2}$ sobre o contar e estabelecer um recorte em relação às implicações desse percurso na formação de professores. $\mathrm{O}$ referencial em que se baseia a discussão aqui proposta são os conceitos do Círculo de

\section{Bakhtin.}

O que costumamos designar por Círculo de Bakhtin compreende, na verdade, o conjunto de grupos de discussão, pesquisa, estudo e publicação de textos filosóficos, filológicos, linguísticos, literários, entre tantos assuntos, dos quais participou o filósofo da linguagem Mikhail Bakhtin. No presente texto, serão mobilizados os conceitos de diálogo e de arquitetônica.

Para os autores desses grupos, o diálogo é um conceito fundante da linguagem. Bakhtin diz que "Nós não perguntamos à natureza e ela não nos responde. Colocamos as perguntas para nós mesmos e de certo modo organizamos a observação ou a experiência para obtermos a resposta" (BAKHTIN, 2011, p. 319).

Assim, é sempre sobre nós mesmos que falamos. É sobre nossa condição no mundo e na vida que nos debruçamos. Nossa história é o trajeto da construção de uma memória do que fizemos, de como nos vemos fazendo e de como representamos para nós mesmos o que os outros pensarão de nós - no tempo e no espaço. Como sujeitos que são, mais que seres do mundo, seres que se posicionam, em duplo sentido.

Em primeiro lugar, porque só são o que são (o que somos), porque ocupamos um lugar único no mundo, que pode ser visto do ponto de vista do outro e somente de onde podemos atribuir uma noção de inteireza e de acabamento (ainda que provisório a esse outro).

\footnotetext{
${ }^{2}$ Axiologia pode ser compreendida como "Teoria do valor geral, compreendido no sentido moral. " (DUROZOI et al, 2005, p. 48)
}

Revista Devir Educação, Lavras, vol.2, n.1, p.55-67, jan./jun., 2018. 
Reciprocamente é somente desse lugar externo a nós, extralocalizados que somos capazes de nos ver por inteiro, quase como o outro nos vê.

Em segundo lugar, porque é desse lugar único que ocupamos que exercemos nosso ato de existir e de produzir, no diálogo com o outro, sentidos sobre nós, sobre ele e sobre o mundo. Tomamos uma posição, em relação à qual, como diz Bakhtin, há um não-álibi, não há desculpas para a não participação da constituição do outro, do mundo e nós mesmos.

Nesse duplo movimento, construímos a nossa permanência, nossa memória, nossa temporalidade. O corpo que nossos olhos vislumbram no espelho, mas que nos desafia pela própria não-coincidência, por um excedente entre o que a face espelhada nos diz sobre a face humana e o que a perplexidade desse rosto nos devolve é, mutuamente, co-construção, fruto da interação constitutiva com o outro e memória de cada passo que percorremos nesse estarjunto.

Para esmiuçar esse diálogo inescapável em cada ato de linguagem, outro conceito bakhtiniano importante é o de arquitetônica. Em sua obra Para uma filosofia do ato, Bakhtin nos diz que

É esta arquitetônica do mundo real do ato que a filosofia moral deve descrever, não como um esquema abstrato, mas como o plano concreto do mundo do ato unitário singular, os momentos concretos fundamentais de sua construção e da sua disposição recíproca. Estes momentos fundamentais são: eu-para-mim, o outro-para-mim, e eu-para-o-outro; todos os valores da vida real e da cultura se dispõem ao redor destes pontos arquitetônicos fundamentais do mundo real do ato: valores científicos, estéticos, políticos (incluindo também os éticos e sociais) e finalmente religiosos. (BAKHTIN, 2010, p. 114)

Diversamente da tradição dos estudos linguísticos estabelecida no Ocidente a partir do Curso de Linguística Geral, o Círculo de Bakhtin toma como constitutiva essa relação intersubjetiva na própria constituição de cada signo e no Grande Tempo que coloca todos os atos de linguagem em diálogo. A arquitetônica é o circuito dessa intersubjetividade. É em torno dessa tríade (eu-para-mim, outro-para-mim e eu-para-o-outro) que pretendemos desenvolver essa reflexão.

\section{Uma contação sobre o contar}

Revista Devir Educação, Lavras, vol.2, n.1, p.55-67, jan./jun., 2018. 
Para contextualizar essa discussão, partiremos, inicialmente, de um contação alegórica do suposto momento inicial da gênese do contar.

Na noite dos tempos, em torno de uma fogueira, animais que andavam, sonhavam e tremiam, se aqueciam no medo das feras e das trevas do desconhecido, entre um lapso e outro de sol.

Em cavernas ou clareiras, a perplexidade era a mesma dos olhos das galinhas e dos lobos. O mundo era sempre novo, a cada acordar.

Num momento que só as nossas mitologias podem adivinhar, dois seres se entreolharam de maneira diferente e se perceberam olhando um para o outro. Talvez, outros diriam mais tarde, tivessem descoberto, antes nos olhos, o efeito que os espelhos fariam sobre suas almas.

Nesse exato instante, nasceram muitas coisas. Uma delas foi a consciência de estarem ali. Mais do que isso, a consciência de saberem estar ali, um diante do outro. E ainda: a consciência e a necessidade de contar para o outro essa descoberta.

Como saber, para além do invólucro de cada corpo, se o outro sabia o que esse eu tinha descoberto. Como saber se o outro o percebia como esse eu percebia o outro corpo, apartado, na distância de um passo e no tempo de sair do próprio lugar? Como descobrir se, para esse outro corpo, as sensações dessa descoberta eram igualmente maravilhosas e assustadoras?

Não sabemos, não saberemos com precisão, como foi essa epifania e menos ainda saberemos se essa pulsão de contar para o outro, de perguntar para o outro, se deu por gestos ou por grunhidos, ou por uma combinação dos dois.

Sabemos de uma palavra que nasceu siamesa da consciência, gêmea do relato, prenhe da necessidade de conhecer a si e ao outro. Nascia a humanidade, a palavra, o contar e o saber. ${ }^{3}$

\section{Contar as histórias, contar a história}

O relato nasce próximo das celebrações rituais e de um historiar os próprios atos. Esses relatos iniciam-se, em todas as culturas, na modalidade oral. Isso deveria parecer óbvio,

\footnotetext{
${ }^{3}$ Autoria própria.
}

Revista Devir Educação, Lavras, vol.2, n.1, p.55-67, jan./jun., 2018. 
mas seis mil anos de escrita desfocaram a percepção de um processo em que estamos profundamente imersos no cotidiano, mas que teimamos, sem nos darmos conta, de olhar exclusivamente pelo viés da escrita.

As danças, os folguedos, as recitações, brincadeiras, os atos celebratórios de iniciações sociais, conjugais, religiosas, fúnebres ou políticas revestem-se, todos eles, não somente de gestos perlocutórios ${ }^{4}$ - aqueles em que as palavras realizam exatamente o que dizem - mas, sobretudo, de um historiar sobre os motivos de aquele grupo, aquela comunidade atribuir sentido ao fazer que está acontecendo.

A noção de acontecimento interessa-nos aqui, de maneira especial. Da perspectiva que assumimos aqui, não há jamais fatos. Dessa palavra veio, também, a palavra feitos. A história e a poesia nascem exatamente dos relatos dos feitos. Mas, como observa Gagnebin (1997),

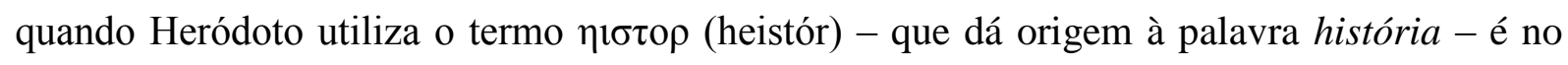
sentido de testemunha, daquele que viu acontecer. Ainda, segundo a autora, outro fundador da disciplina histórica, Tucídides esclarece o modo de construção de seu relato:

Tais discursos, portanto, são reproduzidos com as palavras que, no meu entendimento, os diferentes oradores deveriam ter usado, considerando os respectivos assuntos e os sentimentos mais pertinentes à ocasião em que foram pronunciados... (GAGNEBIN, 1997, p. 28)

Se há em Heródoto uma preocupação retórica - não no sentido de mero ornamento do discurso - e estilística de ornamentar com anedotas e com um estilo agradável ao ouvinte, em contrapartida a um estilo mais austero de Tucídides, há em ambos, a justa medida grega. Existe, assim, um narrador que, embora testemunhe os feitos ou os relatos de quem os presenciou, intermedeia, com seu ponto de vista, o que vai ser narrado.

O ponto que interessa nas recônditas origens das narrações informais no interior de cavernas ou dos textos fundadores de uma ciência histórica (se é que podemos concordar com essa denominação) é exatamente a posição do narrador. Gagnebin introduz toda essa discussão sobre as práticas narrativas de Heródoto e Tucídides em torno de três aspectos: "a construção da memória do passado, a questão da causalidade e a posição do narrador" (p. 15).

\footnotetext{
4 “Na teoria dos actos de fala considera-se efeito perlocutório tudo o que é alcançado ou produzido por meio do acto de dizer algo: convencer, persuadir, surpreender, etc.. " (http://www.portaldalinguaportuguesa.org)
}

Revista Devir Educação, Lavras, vol.2, n.1, p.55-67, jan./jun., 2018. 
Os gregos desconfiavam da memória como relato aceitável dos eventos. Hoje temos algo diferente: as tecnologias de registro. Nossa época acredita na verdade da câmera. É de se questionar, no entanto, em que medida, as três questões acima deixam de estar presentes tanto nas narrativas em torno da fogueira, nos atos celebratórios de cada cultura, nos textos literários canônicos, no texto doutrinal da análise historiográfica ou nos registros audiovisuais?

Deixa de existir a posição do narrador, que escolhe uma perspectiva, que edita e monta sua narrativa, seja com palavras, silêncios, ritmos ou com um software de edição e áudio e vídeo? Obviamente, não.

O acontecimento não pode ser visto como um instante congelado. Ao contrário, emerge como evento que congrega os sujeitos que lhe atribuem sentidos. Para Bakhtin, não cabe olhar para o evento como um recorte fragmentário do tempo:

A aptidão para ver o tempo, para ler o tempo no espaço, e, simultaneamente, para perceber o preenchimento do espaço como um todo em formação, como um acontecimento, e não como um pano de fundo imutável ou como um dado preestabelecido. (BAKHTIN, 2011, p. 225)

Para se compreender a concepção bakhtiniana, é necessário ir além da própria noção de acontecimento. $\mathrm{O}$ acontecimento se constitui como ato, no interior da arquitetônica, da relação intersubjetiva. É na mútua constituição dos sujeitos que seus atos os comprometem, os responsabilizam pelo lugar que cada um ocupa, pelo lugar de onde pode ver o outro. Mas não é qualquer ato, um ato em sentido genérico, abstrato. Em russo é postupok: "Postupok”, ato, contém a raiz "stup" que significa "passo", ato como um passo, como iniciativa, movimento, ação arriscada, tomada de posição. ' (PONZIO in BAKHTIN, 2010, pp. 9-10).

Nessa condição o ato (postupok) não é somente agir sobre o/no mundo. É, também, um relato de quem são esses sujeitos que se congregam na interação, que se unem ao redor de uma mesma fogueira, de um mesmo cômodo, ou mesmo sob uma redoma de um metafórico céu noturno para contar sobre si, sobre os que ouvem, sobre o mundo que os abriga nesse gesto mesmo de contar.

Michael Holquist, em seu prefácio para a edição norte-americana de Para uma filosofia do ato, de Bakhtin, estabelece uma relação entre o ato e relato:

Revista Devir Educação, Lavras, vol.2, n.1, p.55-67, jan./jun., 2018. 
ISSN: 2526-849X

Para Bakhtin, a unidade de um ato e seu relato, uma ação e seu significado, se preferir, é algo que nunca é um a priori, mas que deve sempre e em toda parte ser conquistado. $\mathrm{O}$ ato é uma ação, e não um mero acontecimento (como em 'uma maldita coisa depois da outra'), apenas se o sujeito de tal postupok, de dentro de sua unicidade radical, tece uma relação com ele em seu relato dele. A responsabilidade, então, é a fundação da ação moral, o modo pelo qual nós superamos a culpa da cisão entre nossas palavras e nossas ações, mesmo que não tenhamos um álibi na existência - de fato, porque não temos tal álibi: 'É apenas o meu não-álibi no Ser que transforma uma possibilidade vazia em um ato ou ação responsável e real...' (p. 44 da presente tradução). (HOLQUIST in BAKHTIN, 1993, pp. 9-10)

Portanto, construir esse relato, essa contação é ser testemunha não de um fato, a priori. É estar num evento que é constituído e constituinte da intersubjetividade, da alteridade. De um diálogo. Os gregos, no início da construção de um saber que viríamos, mais tarde, a chamar de história, situavam-se nessa condição necessária para qualquer relato: há um ritual e um auditório, que diferem em cada situação em que o orador irá recitar seu testemunho. $\mathrm{O}$ feito não é, ao contrário de nossas posteriores tradições cartesianas e positivistas, algo que vale por si. É realizado por seres humanos e contado, também, por seres humanos.

\section{Recontar o contado}

Se até aqui nos detivemos sobre narrativas informais e históricas, abordaremos, agora, os relatos de relatos. Cabe, para isso, invocar Volóchinov, em Marxismo e Filosofia da Linguagem, quando discute o discurso direto:

A preparação do discurso citado e a antecipação de seu tema e das suas avaliações e ênfases pela narrativa do autor podem tornar o contexto autoral tão fortemente subjetivizado e marcado com os tons do personagem que esse mesmo contexto passa a soar como um "discurso alheio", dotado, no entanto, de entonações autorais. (VOLÓCHINOV, 2017, p. 280)

Lembremo-nos que, para os autores do Círculo de Bakhtin, não há ato de linguagem que não seja diálogo. Os seres em torno da fogueira, que, de repente, se percebem humanos, o

\footnotetext{
${ }^{5}$ Bakhtin, ainda diz que "Um ato realizado é ativo no produto único real que ele produziu (numa ação real, atual, numa palavra enunciada, num pensamento que foi pensado, onde, além disso, a validade em si, abstrata, de uma lei jurídica real é apenas um momento constituinte). (BAKHTIN, 1993, p. 44)
} 
fazem por compartilharem a linguagem e a consciência. Uma consciência necessariamente interconectada, interdependente, alteritária:

Assim, a personalidade que se exprime, apreendida, por assim dizer, do interior, revela-se um produto total da inter-relação social. A atividade mental do sujeito constitui, da mesma forma que a expressão exterior, um território social. Em consequência, todo o itinerário que leva da atividade mental (o "conteúdo a exprimir") à sua objetivação externa (a "enunciação") situa-se completamente em território social. (BAKHTIN/VOLOCHINOV, 2006, p. 112)

E cada um desses seres, ao representar o outro, a si mesmo e a tentar antecipar como o outro o representa (o que Bakhtin chama de arquitetônica), investe cada ato e cada pensamento, cada palavra ou cada silêncio que recheia seus enunciados com uma entonação, com um modo unicamente seu de estar no mundo e de se enxergar e de enxergar ao outro. $\mathrm{O}$ relato, a contação, não são imunes ao que cada ser humano é, ao que o constitui.

Assim, recontar, seja na elocução, seja na leitura - porque a leitura, mesmo silenciosa, é, também, um modo de recontar algo -, é investir aquele relato de uma atualização do que aquela pessoa, persona, vive na sua passagem no tempo, no espaço e na cultura, pela existência.

Do ponto de vista dessa concepção, o contato com a produção literária e estética não cabe ser pensado como mera informação ou reprodução. Jorge Luís Borges, quando fala sobre o livro diz algo parecido:

\footnotetext{
Heráclito disse (demasiadas vezes o tenho repetido) que ninguém se banha duas vezes nas mesmas águas de um rio. Ninguém se banha duas vezes no mesmo rio porque as águas mudam, mas o que é mais terrível é que nós não somos menos fluidos do que o rio. De cada vez que lemos um livro, o livro não é o mesmo, a conotação das palavras é outra. [...] Hamlet não é exatamente o Hamlet que Shakespeare concebeu no princípio do século XVII; Hamlet de Coleridge, de Goethe e de Bradley. Hamlet foi ressuscitado. O mesmo acontece com o Quijote. O mesmo acontece com Lugones, Martínez Estrada, o Martín Fierro não é o mesmo. Os leitores foram enriquecendo o livro. (BORGES, 1999, p. 29)
}

Portanto, há que se considerar, da perspectiva da arquitetônica, que nem sequer o mesmo ser biológico que relê um texto, que reconta uma piada, empreende uma repetição. Entre o que chamamos de céu e terra, talvez sejamos condenados a nunca repetir sequer um 


\section{QO DEVIR EDUCAÇÃO}

ISSN: 2526-849X

único gesto, um único ato. Inscritos na relação simultânea e mutuamente constitutiva de nós mesmos e dos outros que coparticipam, também, de nossa constituição, cada narrativa que fazemos é sempre a da criação.

E, então, o que é recontar, senão, saber-se localizado num tempo e numa cultura, num modo de enunciar, pelo diálogo, o que nos constitui e o que/a quem constituímos? Podemos invocar VOLÓCHINOV ([1930] 2005, p. 8) para nos ajudar com a noção de diálogo:

Nós sabemos que todo discurso é um discurso dialógico orientado em direção a alguém que seja capaz de compreendê-lo e dar-lhe uma resposta, real ou virtual. Esta orientação em direção ao "outro", em direção ao ouvinte, conduz necessariamente a se levar em conta a relação social e hierárquica que existe entre os interlocutores.

E podemos complementar, ainda, com Volóchinov:

Toda compreensão é dialógica. A compreensão opõe-se ao enunciado, assim como uma réplica opõe-se a outra no diálogo. A compreensão busca uma antipalavra à palavra do falante. (VOLÓCHINOV, 2017, p. 232)

O que nos interessa nessas noções de diálogo é ressaltar que no interior da arquitetônica, há que se considerar essa orientação constitutiva do discurso. E, por discurso entendemos aqui essa palavra viva, nascida dessa dupla necessidade do eu e do outro, de maneira que ao ser enunciada, já traz em si a condição de réplica à palavra que a antecede e à palavra que deseja provocar como resposta, seja na compreensão da palavra anterior, seja na forma da espera e da provocação de outra palavra.

\section{Considerações finais: e a formação de professores?}

Se, como pretendemos discutir até agora, relatar, contar, narrar é inevitavelmente um contar junto, um contar para si e para o outro, um escutar a própria voz dizendo para o outro, um escutar a escuta do outro e como sua voz responde à nossa, provoca a nossa, então, nossas práticas como cidadãos e como professores dimensionam-se de maneira diferente. 


\section{Q DEVIR EDUCAÇÃO}

ISSN: 2526-849X

Da perspectiva da arquitetônica e do diálogo - constitutivos, inescapáveis - não se concebe o professor como um transmissor, nem de conhecimentos e de narrativas que petrificam esses conhecimentos, nem sequer como um mero narrador de fatos passados.

Como qualquer falante/ouvinte/compreendente ${ }^{6}$ envolvido com outros sujeitos na produção, circulação e recepção de sentidos nas/pelas linguagens, o professor é um mediador, com uma escolha que o responsabiliza ainda mais: o que torna a linguagem interessante para nossos olhares perplexos é a de que a constituímos, mas somos igual e simultaneamente constituídos por ela.

Ao tratarmos qualquer ato de linguagem como realidade em si, inclusive as imagens de uma câmera ou uma cobertura midiática, estamos, como professores, deixando de olhar para o que a linguagem é e para o que somos: ambos produtos e processos de uma complexa arquitetônica que nos faz participar do mundo e o (re)construir por meio das maneiras como o vemos/nos vemos e o redizemos, recontando-nos continuamente. É com esse fluxo de vida que somos responsáveis no interior do diálogo e da arquitetônica.

Dito isso, é importante explorarmos rapidamente outra face dessa palavra que se conta e se faz contar. Jorge Luís Borges diz que "Talvez a história universal seja a história de algumas metáforas." (BORGES, 1999, p. 12). Poderia ser igualmente uma história de metonímias. As noções de recorte e de delimitação, tão caras ao nosso cotidiano acadêmico, são basicamente metonímicas. Tomamos um signo, uma parcela do mundo em substituição a outro e vamos encadeando esses índices de nossa representação do mundo.

Mas podemos tomar o contar e o recontar como uma trajetória de hipérboles. Em algum sentido, podemos considerar o épico, fundante de nossa tradição literária, como um processo de produção de sentidos assentado na hipérbole. Figura de linguagem assentada no exagero, pode-se dizer que,

Sua função é fornecer uma referência que, numa dada direção, atrai o espírito, para depois obrigá-lo a retroceder um pouco, ao limite extremo do que lhe parece compatível com a sua ideia do humano, do possível, do verossímil, com tudo o que ele admite de outro ponto de vista. (PERELMAN; OLBRECHTS-TYTECA, 2000, p. 331)

\footnotetext{
${ }^{6}$ Tríade que Bakhtin/Volóchinov entendem constituir a interação na/pela linguagem.
} 


\section{Q DEVIR EDUCAÇÃO}

ISSN: 2526-849X

Há, portanto, na hipérbole, subjacente a um efeito de sentido de exagero, um diálogo que podemos situar dentro da arquitetônica bakhtiniana. Há um movimento, um gesto do ponto de vista do enunciador que representa a si como uma posição investida de uma autoridade doutrinal, que vai mostrar a verdade para o outro (o outro para si) por meio do assombro. Há, também, uma representação implícita, aquela que o enunciador tem da imagem que o enunciatário tem dele, enunciador. Aqui, a vizinhança etimológica entre autoria e autoridade faz-se apresentar com mais nitidez. É concebendo que o leitor irá tomar o autor como fonte de um saber, uma autoridade na verdade que vai mostrar, que esse autor irá pôr a cabo seu empreendimento retórico. E o faz, ab-usando (usando para além) da semelhança que o seu dizer possa ter com a verdade. E exatamente porquê vê nesse fazer com a linguagem um meio de levar a verdade para o leitor/ouvinte.

É nessa direção que vai o que comentam Charaudeau e Maingueneau sobre a hipérbole. Para os autores, ela

Pode aumentar ou diminuir por excesso, e as representa bem acima ou bem abaixo daquilo que são, não com finalidade de enganar, mas de levar à própria verdade, e de fixar, pelo que é dito de inacreditável, aquilo que é preciso realmente crer. (CHARAUDEAU; MAINGUENEAU, 2008, p. 262)

É possível dizer que a constituição do herói é hiperbólica. Revestimos uma dada representação (ou um conjunto de representações) do outro, no calor do cotidiano e o sobredizemos. Não é de hoje, nem de nosso contexto sociocultural específico que surgiu essa forma de contar. No entanto, ao atualizarmos essa forma de (contar) história, cabe nos interrogarmos quem erigimos como heróis, nesse processo de sobredizer e, aproveitando o conceito de arquitetônica, o que isso diz de nós e dos outros para quem contamos e do porquê contamos dessa maneira, para esses sujeitos.

Nesse sobredizer, sobrepomos aos signos que o designam uma entonação, indiciadora do enunciador, daquele que conta, somada à representação que esse enunciador tem do enunciatário, daquele para quem se conta. Assim, no jogo de representações da arquitetônica, temos um jogo de réplicas entre o signo que tomamos como palavra outra, como história a ser recontada, a entonação, o lugar no mundo do enunciador e o lugar no mundo do enunciatário.

Destacaríamos dois aspectos muito atuais dessa constituição hiperbólica do recontar. O primeiro, pelo exagero na modalização. Vivemos uma cultura e uma época obcecada pela 


\section{QO DEVIR EDUCAÇÃO}

ISSN: 2526-849X

caricatura, pelo grotesco e pelo enfático ${ }^{7}$. O segundo, por uma temporalidade verticalizada. Nossas crianças demandam uma repetição obsessiva do ver, ouvir, receber o relato. Nossos gostos musicais são rápidos, saturantes e rapidamente descartáveis.

No início desse artigo, recontamos, sob um gênero mais literário, uma possível origem da linguagem e de nós como seres humanos. Da perspectiva desse reconto, somos todos filhos de nossa consciência de nosso dizer/fazer na/pela linguagem.

Como uma pequena provocação final, podemos considerar que o papel do professor é se pensar no interior dessa arquitetônica em uma dupla instância. De um lado, como sujeito do/no mundo, participante desse circuito de produção/circulação/recepção de sentidos. De outro, como mediador, como outro de seus alunos no interior da arquitetônica. Desconsiderar essa mútua constituição e nossas responsabilidades com nós mesmos, com os outros e com a própria linguagem não deixa de ser uma forma abrir mão da vida e da linguagem. Simultaneamente, uma morte de si, uma morte do outro, uma morte da linguagem e da própria condição de se viver. Se assim, for, haverá o que contar? Haverá sentido em se (re)contar ?

\section{Referências}

BAKHTIN, Mikhail Mikhailovich.Estética da criação verbal. Tradução do russo por Paulo Bezerra. 7. ed. São Paulo: Martins Fontes, 2011.

Para uma filosofia do Ato. São Carlos: Pedro \& João Editores, 2010.

Para uma filosofia do ato. Tradução de Carlos Alberto Faraco e Cristóvão Tezza a partir da edição norte-americana Towards a Philosophy of Act, traduzida do russo por Vadim Liapunov. 1993. Mimeo.

BAKHTIN, Mikhail Mikhailovich./ VOLÓCHINOV, Valentin. Marxismo e Filosofia da Linguagem. 12. ed. São Paulo: Hucitec, 2006.

BORGES, Jorge Luis. A esfera de Pascal. Outras Inquisições. In Obras Completas. Volume II. São Paulo: 1999.

BORGES, Jorge Luis. Borges Oral. Lisboa: Editora Vega. SD.

DUROZOI, Gérard; ROUSSEL, André; APPENZELLER, Marina. Dicionário de Filosofia. Campinas/SP: Papirus, 2005.

GAGNEBIN, Jeanne Marie. Sete aulas sobre Linguagem, Memória e História. Rio de Janeiro: Imago, 1997.

\footnotetext{
${ }^{7}$ Não discutiremos aqui, mas vale atentar para um jogo de réplicas entre ênfase e silêncio. Quanto mais enfático um enunciado, há probabilidade de que sua réplica seja um silêncio, seja pelo gesto silenciador que essa ênfase empreende, seja pela recusa do enunciatário em partilhar do sobredizer enfático.
}

Revista Devir Educação, Lavras, vol.2, n.1, p.55-67, jan./jun., 2018. 
CHARAUDEAU, Patrick; MAINGUENEAU, Dominique. Análise de textos de comunicação. São Paulo: Cortez, 2008.

PERELMAN, Chaïm; OLBRECHTS-TYTECA, Lucie. Tratado da argumentação: a nova retórica. São Paulo: Martins Fontes, 2000.

PORTAL DA LÍNGUA PORTUGUESA. Disponível em http://www.portaldalinguaportuguesa.org. Acesso em 28 de abril de 2017.

VOLOCHINOV, VOLÓCHINOV, Valentin. Marxismo e Filosofia da Linguagem: problemas fundamentais do método sociológico na ciência da linguagem. Trad. e notas de Sheila Grillo e Ekaterina Volkova Américo. São Paulo: Editora 34, 2017.

A estrutura do enunciado. Trad. de Ana Vaz, para fins didáticos, com base na tradução francesa de Tzvetan Todorov ("La structure de l'énoncé, 1930). In: TODOROV, Tzvetan. Mikhail Bakhtine: le principe dialogique. Paris: Seuil, 2005. p. 287316. 